\title{
Student Network Lifestyle regularity and Model
}

\author{
Jingjing Yan \\ Beijing University of Posts and Telecommunications, School of Science, Beijing, China \\ yanjingjing88@bupt.edu.cn
}

\section{Keywords: Network lifestyle; Factor analysis}

\begin{abstract}
Network lifestyle is a hot issue for scholars in recent years, it have a profound impact to college students living, learning, cognitive and even values. In this study, based on lifestyle measurement methods in sociological research, to get the concept, content and analysis model of network lifestyle, to research the network living status of Beijing Posts and Telecommunications University Students through questionnaires, and made relevant educational recommendations based on the type of students network and the classification guide through the statistical methods of factor extraction and clustering analysis.
\end{abstract}

\section{Introduction}

The rise of the Internet makes the media is no longer just a tool for information transfer, but created a new digital and information technology, networking social living space, and thus changing people's behavior, thinking, social relations. In this context, the impact of the Internet for college students is even more far-reaching.

In today's information age, the Internet has become an important platform for college students to learn, exchange ideas and entertain. How to delve into students' network lifestyle, to build a healthy and positive network lifestyle based the principles to promote the advantages and avoid the disadvantages, to eventually propose some appropriate methods and guidance, are become an urgent focus of research.

According to current widespread use of the network in university students, the university student network behaviors mainly research the followings:

Table 1 Student network lifestyle scale

\begin{tabular}{|c|l|}
\hline Network Behavior & \multicolumn{1}{c|}{ Research Content } \\
\hline E-learning & $\begin{array}{l}\text { 1. The use of free video courses provided by various domestic and } \\
\text { international educational institutions (such as MIT, Yale, etc.) } \\
\text { 2. The use of various types of digital libraries (such as CNKI, Google Scholar, } \\
\text { etc.) } \\
\text { 3. To download learning resources through the course center, online } \\
\text { education platform, FTP and others } \\
\text { 4. Search learning materials through a variety of search engines and other } \\
\text { tools }\end{array}$ \\
\hline Network social & $\begin{array}{l}\text { 1. Using social networking sites (QQ space, Renren, etc.) } \\
\text { 2. Microblogging use web publishing (such as Sina Weibo, Tencent Weibo, } \\
\text { etc.) } \\
\text { 3. Use dating platform (such as ChinaRen alumni, friends, network, etc.) } \\
\text { 4. Use instant messaging tools (such as QQ, MSN, flying letters, email, etc.) }\end{array}$ \\
\hline
\end{tabular}




\begin{tabular}{|c|l|}
\hline Network & $\begin{array}{l}\text { 1. Browse all kinds of news (municipal, entertainment, sports, etc.) } \\
\text { 2. Use video sites (such as PPTV, watercress, etc.) to listen to music, watch } \\
\text { movies, TV shows, etc. } \\
\text { 3. Download tools (such as eMule, Thunder, etc.) to download music, } \\
\text { movies, TV shows, etc. }\end{array}$ \\
\hline Ontertainment shopping & $\begin{array}{l}\text { 1. Online shopping (such as clothes, video, electronic products, etc.) } \\
\text { 2. Sell items through secondary trading networks (like the urban network) }\end{array}$ \\
\hline
\end{tabular}

\section{Students network lifestyle measurement system}

On the basis of specific research background and content, this paper presents the measurement system of university student network lifestyle, including "network uses motivation," "network uses ability", "Internet usage" and "network usage attitude." "Internet usage" mainly consists of the learning, social, entertainment and shopping of university students network behavior. Here, we introduce a dimension of " network uses ability " as a comprehensive index to measure the ease of users to understand the network operation.[1] Sturgill \& Martin, who pointed out in the study: If students do not have adequate computer skills in the use of computer as mediated communication tools, there will be psychological feelings of frustration. This also shows that the ability level to use the network of different groups of people has some differences using behaviors in their use of new network tools.

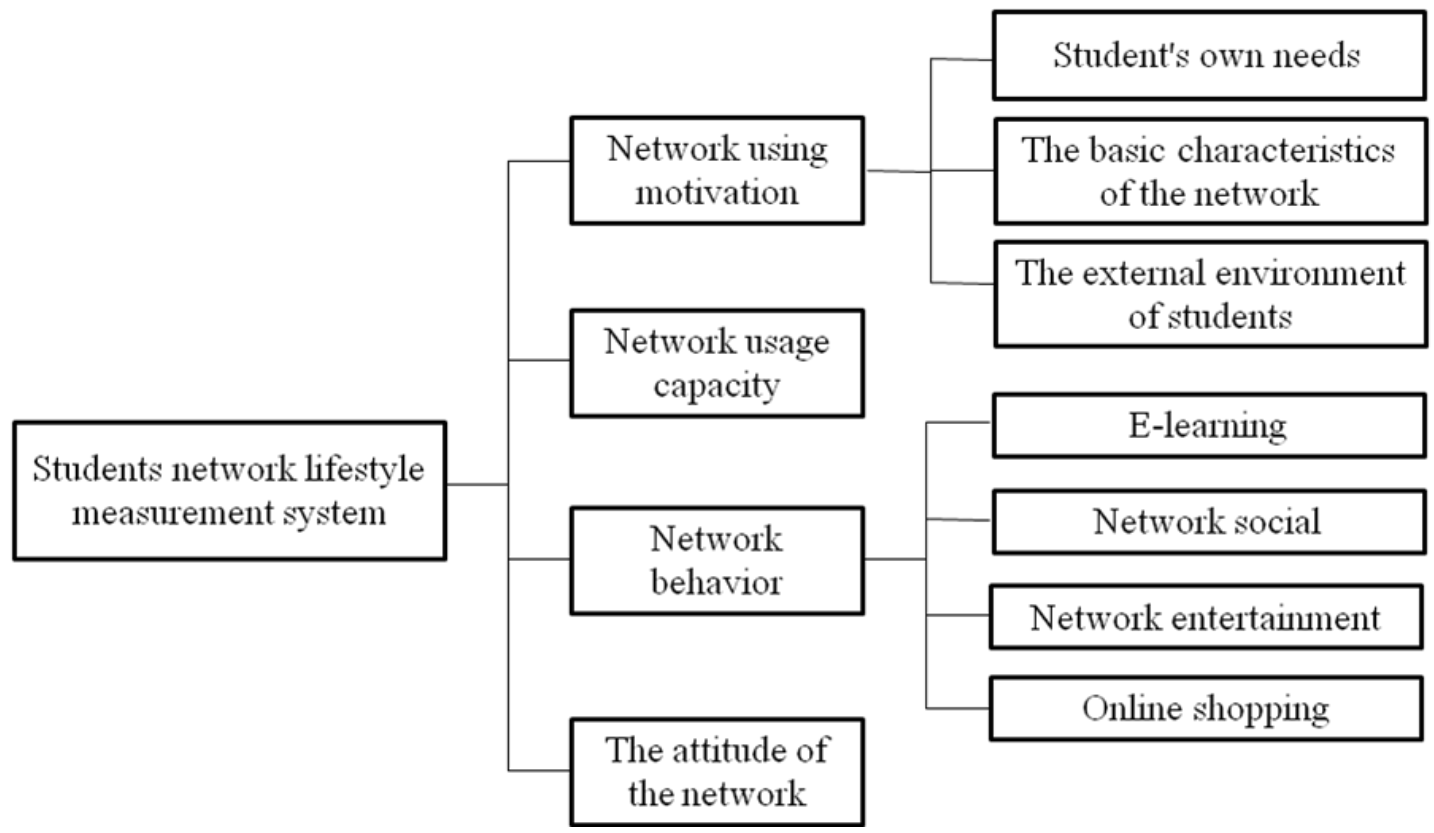

Fig. 1 Student network lifestyle chart

\section{Student Network Lifestyle Scale}

This paper focuses on students' network lifestyle, this theme determines the need to adopt an effective way to collect a large amount of research data for the school at all levels of students. Therefore, it is the most important way to get valid data from different types of school students of different grades in different colleges in accordance with the principles of stratified sample.

Questionnaire design. Combined with our literature research and long-term student work experience, follow the questionnaire design principles, to design the questionnaire of students' network lifestyle, the survey included six categories: background information, network usage time and 
activities, network using motivation, network usage capacity, network behavior and attitudes to the network.

(1) Background information: basic information, including grade, gender, profession, whether it has a computer, the main Internet sites, network age, and time spent online. Survey questions included the proportion of students have computers, students Internet time on weekdays, holidays and other issues.

(2) Internet usage time and activities: mainly investigate the reliance of student to network, including whether students will becoming restless after a period of time without the Internet, whether online time is longer than previously planned; [2]whether students had tried hard to shorten the online time, but always failed; whether spent most online time for learning all aspects of knowledge; whether ever overnight online experience and other issues.

(3) Network using motivation: including ways to get the website address, the main purpose of the Internet, which content will be first open in the Internet, which content occupy the longest time, whether to get information online through paid, and What is the preferred way to seek learning experience, so these problems.

(4) Network usage capacity: mainly used to measure the difficulty of operating a network of students, including those using web browser software, basic computer skills and methods, network technology and other aspects.

(5) Network behavior: mainly used to survey the impact of network on student learning and life, which included the online activities which students generally considered most likely to lead to addiction, included students whether considered that the network was more helpful for their own learning, whether regularly or occasionally regret spent too much time in the internet, included students whether think the internet have a greater negative impact to their learning and living, etc.

(6) The attitude of the network: whether students believe that the network is virtual, should not be too serious in the process of using the network (or even "completely irresponsible"); [3]believe it does not matter that the use of uncivil language (or even often use) when in the Internet and other issues.

According to the study of college student network behavior composition and college network lifestyle measurement system, we designed a complete network lifestyle questionnaire in this study, which representative and operability covering all aspects of e-learning, social, entertainment and shopping of university students.

Data analysis. Within a period of four months, we have received a total of 783 copies of questionnaires, including 749 copies of valid questionnaires, questionnaires efficiency of $95.6 \%$. Students participate in the survey, $96 \%$ of them own at least a computer. Among them, $93 \%$ of students have laptops, $3 \%$ of the students have the desktop computers. In the 749 valid questionnaires, only $2 \%$ of low-grade students do not have computers, but they said have the upcoming purchase. In the survey of the frequency of use the Internet, $78 \%$ of students said they use Internet every day, also there are many students online 3 to 4 times a week, accounting for $39 \%$ of the total, only a few students chose occasional use Internet.

In the investigate of students' beginning online time, the researchers found that 58 percent of students has started the Internet regularly in high school (including junior high and high school), 29 percent of students in the familiar with network at the elementary school, while only $11 \%$ of students start use network in college.

In the survey of the most frequently performed activities of college students, the data show that the vast majority of students chose to search and download learning materials on the Internet; it is followed by 351 students choose to use social networks to socialize; browse news, watch and download video entertainment is also the most important purpose of students network living.

In the survey, we also found that $87 \%$ of the students have done and are doing online learning, they represent there are a wealth of resources in the internet, which is facilitate to learning through the network and get the latest information. Of course, there is also a small group of students has a negative 
attitude for online learning, mainly concentrated in the maneuver, a waste of time and do not know how to choose the right resources.

Online shopping is the main content of the student network life. Survey shows that $57 \%$ of students regularly conduct online shopping, mainly about books, audio and video products and clothes, shoes and other items. On the causes of network consumption, fast and easy, affordable and cheap, convenient to become the main reason for students' network consumption, but most students chose that network consumption is less reliable. There are also some students refused to use the network consumption, they believe that "the network consumption process is complex, cumbersome procedures," "unreliable, worry endanger and personal account security" and "fear of personal information being leaked."

\section{Countermeasures and suggestions}

For the problems of students addicted to the Internet in their network life, to help students adjust the status of addicted to the network, we propose a targeted and actionable solution and specific measures.

The main measures to prevent students from indulging in the network: Teacher led and organize student leaders to dormitory to checks the case that install game within the computer; strengthen supervision and examination for classroom and self-study and other aspects of; promote teachers research team to absorb students, encourage and guide students to participate in research activities under the guidance of teachers; actively organize a variety of cultural activities on campus to guide students to participate in various cultural activities on campus; held an open discussion in students class meetings; requires each student do the public commitment.[4]

The main measures to help students adjust to indulge in the network: teacher should regularly talk and communicate with students; arrange student to help each other one to one; to enhance communication and collaboration with parents; to strengthen communication and collaboration with the classroom teacher; to communicate with students through the network; give students appropriate disciplinary action.

\section{Summary}

Through surveys, statistics and analysis, as the problems of college students in the network living, this study puts forward some suggestions and measures actionable, and has been applied to the actual work. Due to the scope of the measures we propose is still relatively small, need to test its effect on a larger scale, we will continue to track and research to further improve and perfect the relevant recommendations and measures.

\section{References}

[1] Li Yan, Impact of computer networks on Students' Learning Life - Survey Report from Zhejiang University [J]. Higher Engineering Education Research, 2008 (04). (In Chinese)

[2] Liu Lin. Lifestyle and social support on mental health of college students in Wuhan[D]. Central China Normal University, 2008.(In Chinese)

[3] Zheng Siming. Structure and its impact factor of health behaviors of adolescent in the Internet [D]. Capital Normal University, 2007. (In Chinese)

[4] Tang Guozhan. Students lifestyle and guide research [D]. Central China Normal University, 2006. (In Chinese) 